\title{
Penerapan Augmented Reality Video Dinamis dalam Pembelajaran Peredaran Darah Berbasis Android
}

\author{
Ida Ayu Putu Wipra Astiti, Gusti Made Arya Sasmita, Made Sukarsa \\ Program Studi Teknologi Informasi Fakultas Teknik Universitas Udayana \\ Bukit Jimbaran, Bali, Indonesia, telp. (0361) 701806 \\ e-mail: ogekwipra@gmail.com, aryasasmita88@gmail.com, sukarsa@unud.ac.id
}

\begin{abstract}
Abstrak
Peredaran darah merupakan suatu pelajaran penting yang harus diketahui oleh siswa siswi dalam pelajaran biologi. Banyak siswa yang kurang dalam pemahaman saat dijelaskan dengan buku atau alat peraga. Terbatasnya alat peraga dan ketertarikan para siswa untuk belajar mendominasi pemanfaatan alat elektronik sebagai bahan ajar. Teknologi yang semakin canggih dapat dimanfaatkan sebagai sarana belajar mengajar yang menarik. Penerapan teknologi augmented reality dalam pembelajaran peredaran darah menjadi salah satu solusi. Augmented reality video dinamis berbasis android dimanfaatkan untuk membantu minta siswa belajar lebih efektif. Video yang digunakan dapat diambil dari video yang sudah ada ataupun rancangan video animasi sendiri. Aplikasi dikembangkan dengan marker. Fitur yang ditampilkan pada aplikasi memiliki 4 scene, yaitu 3D Statis, Video Dinamis, About dan Exit. Fitur utama aplikasi adalah 3D Statis yang berisi informasi mengenai bentuk jantung dan Fitur Video Dinamis, dimana jika marker di scan akan memunculkan video penjelasan mengenai peredaran darah pada jantung. Hasil dari aplikasi ini yaitu berupa aplikasi yang dijalankan dalam perangkat mobile Android dan dapat memberikan informasi mengenai peredaran darah pada jantung. Kualitas aplikasi menurut penilaian dari responden adalah baik, dengan persentase grafis sebesar $64 \%$, presentase rekayasa perangkat lunak $71 \%$ dan presentase entertainment application yaitu $81 \%$.
\end{abstract}

Kata kunci: peredaran darah, augmented reality, video dinamis, marker, Android,

\begin{abstract}
The importance of knowledge and understanding of students makes the teacher must provide more complete information using teaching aids. Student learning interest is determined by the teaching method of the teacher. Increasingly sophisticated technology can be used as an attractive teaching and learning facility. The application of augmented reality technology in learning blood circulation is one solution. Android-based dynamic video augmented reality is used to help students learn more effectively. The video used can be taken from an existing video or the design of the animated video itself. Application developed with marker. The features displayed on the application have 4 scenes, namely Static 3D, Dynamic Video, About and Exit. The main feature of the application is Static 3D which contains information about the shape of the heart and the Dynamic Video Feature, where if the marker on the scan will show an explanation video about the circulation of blood to the heart. The results of this application is an application that runs in Android mobile devices and can provide information about the blood circulation in the heart. The quality of the application based on the respondents' assessment results is good, with the results of the graphic aspect percentage of $64 \%$, the software engineering aspect of $71 \%$ and the entertainment application aspect of $81 \%$.
\end{abstract}

Keywords: blood circulation, augmented reality, dynamic video, marker, Android

\section{Pendahuluan}

Teknologi Augmented Reality dapat dimanfaatkan untuk merancang sebuah konsep perpanjangan informasi dari media promosi cetak ke media promosi berbentuk video menggunakan teknologi AR. Sistem yang dibangun mampu mengenali marker dan dapat 
menampilkan video yang dibuka melalui URL. Metode pembelajaran yang digunakan untuk mendukung proses kegiatan belajar mengajar saat ini khususnya pada mata pelajaran IPA pengenalan peredaran darah jantung manusia masih menggunakan media buku, LKS, dan menggunakan bahan praktek alat peraga, sedangkan proses pembelajaran yang ada saat ini guru menulis dan menerangkan kemudian siswa mencatat materi yang ditulis oleh guru. Alat peraga yang hanya tersedia 1 unit sedangkan jumlah siswa di kelas kurang lebih ada 30 anak. Keadaan ini menimbulkan suasana yang kurang mendukung bagi siswa-siswi pada saat proses belajar mengajar berlangsung sehingga pemahaman atau penguasaan materi yang di dapat kurang maksimal. Biaya dari alat peraga yang tidak murah merupakan alasan penggunakan Augmented Reality yang mampu merealisasikan dunia virtual ke dunia nyata, dapat mengubah objek-objek tersebut menjadi objek 3D, sehingga aplikasi ini dapat membantu guru dalam menyampaikan materi dalam sistem peredaran darah manusia kepada siswa dan dapat lebih menarik bagi siswa mempelajari materi dalam sistem peredaran darah pada manusia dan juga siswa dapat lebih memahami materi.

Penelitian sebelumnya [1] membahas mengenai Museum Bali dengan rumusan masalah pengunjung yang telah berkurang, sehingga harus dikembangkan inovasi baru dalam mempromosikan Museum Bali. Inovasi yang tepat dalam mempromosikan Museum Bali yaitu dengan Augmented Reality Museum Bali pada Android. Memanfaatkan teknologi baru yaitu augmented reality dengan mendeteksi marker yang telah disediakan kemudian muncul objek 3D dari marker tersebut serta informasi lengkap dari salah satu objek di Museum Bali. Metode ini menjadi pengalaman baru dan menyenangkan bagi setiap kalangan yang ingin tahu lebih banyak tentang Museum Bali

Penelitian sebelumnya [2] membahas mengenai pengenalan binatang untuk siswa TK. Anak-anak berusia 5 hingga 7 tahun, berada di masa keemasan mereka di mana mereka semakin sensitif terhadap stimulus dan lebih mudah dalam mempelajari hal-hal baru, bahwa mereka lebih mudah dalam menerima hal-hal baru dan menarik. Jadi, tampaknya penting bagi anak-anak pada usia ini untuk belajar tentang makhluk hidup di sekitar mereka, salah satunya adalah belajar tentang binatang. Media tentang pengenalan hewan untuk siswa TK, seperti buku dengan bentuk binatang 2 dimensi, sepertinya belum mampu membangkitkan semangat anak-anak untuk belajar tentang spesies hewan. Aplikasi Ajaib Aplikasi Buku Ajar untuk Siswa TK ini telah dikembangkan menggunakan basis Android dengan penanda yang mengidentifikasi objek hewan 3 dimensi, suara mereka, dan informasi tentang hewan menggunakan Teknologi Augmented Reality. Teknologi Augmented Reality membuat pengenalan hewan kepada anakanak menjadi lebih mudah dan lebih menarik, aplikasi ini menunjukkan 3 dimensi bentuk binatang dan suara mereka dengan antarmuka yang lebih inovatif menggunakan Smartphone.

Penelitian sebelumnya [3] membahas mengenai aplikasi media untuk belajar gerakan dasar Tari Bali dapat diakses oleh pengguna smartphone. Teknologi Augmented Reality mampu membuat penerapan pembelajaran gerakan dasar Tari Bali menjadi lebih interaktif dan menarik. Aplikasi ini menggunakan vuforia yang mampu memainkan suara dan menampilkan objek 3D dari gambar gerak dasar Tari Bali sebagai marker, ke sebuah lingkungan nyata. Hasil dari penelitian ini adalah sebuah buku yang berisi informasi dan gambar yang berkaitan dengan gerakan-gerakan dasar Tari Bali yang difungsikan sebagai marker. Android based aplikasi ini mampu menampilkan objek penari dalam 3D dengan posisi dan gerakan dasar Tari Bali di atas marker dan memutar suara yang berisi informasi tentang pergerakan Tari Bali. Tari Bali dalam aplikasi ini juga membant untuk mempertahankan Budaya Bali yang telah menjadi daya tarik bagi wisatawan baik lokal maupun asing.

Penelitian ini bertujuan agar pengguna dapat memvisualisasikan peredaran darah jantung manusia secara 3D dan realtime. Aplikasi dengan menggunakan visual 3D, penggunaan dapat memvisualisasikan bentuk organ jantung manusia secara 3D serta dapat mengetahui fungsi-fungsi organ tersebut dengan lebih mendetail dan nyata. Penggunaan 
Augented Reality peredaran darah jantung ini dapat mempermudah seorang guru menjelaskan kepada seluruh murid-muridnya dengan menciptakan dunia virtual. Murid-murid merasa bahwa pelajarannya sangat menarik dan antusias mengikuti pelajaran.

\section{Metodologi Penelitian}

Pelaksanaan program ini dibagi kedalam beberapa tahap. Perancangan prototype aplikasi serta pembuatan laporan hasil pelaksanaan kegiatan dapat dimodelkan dengan urutan flow chart sebagai berikut.

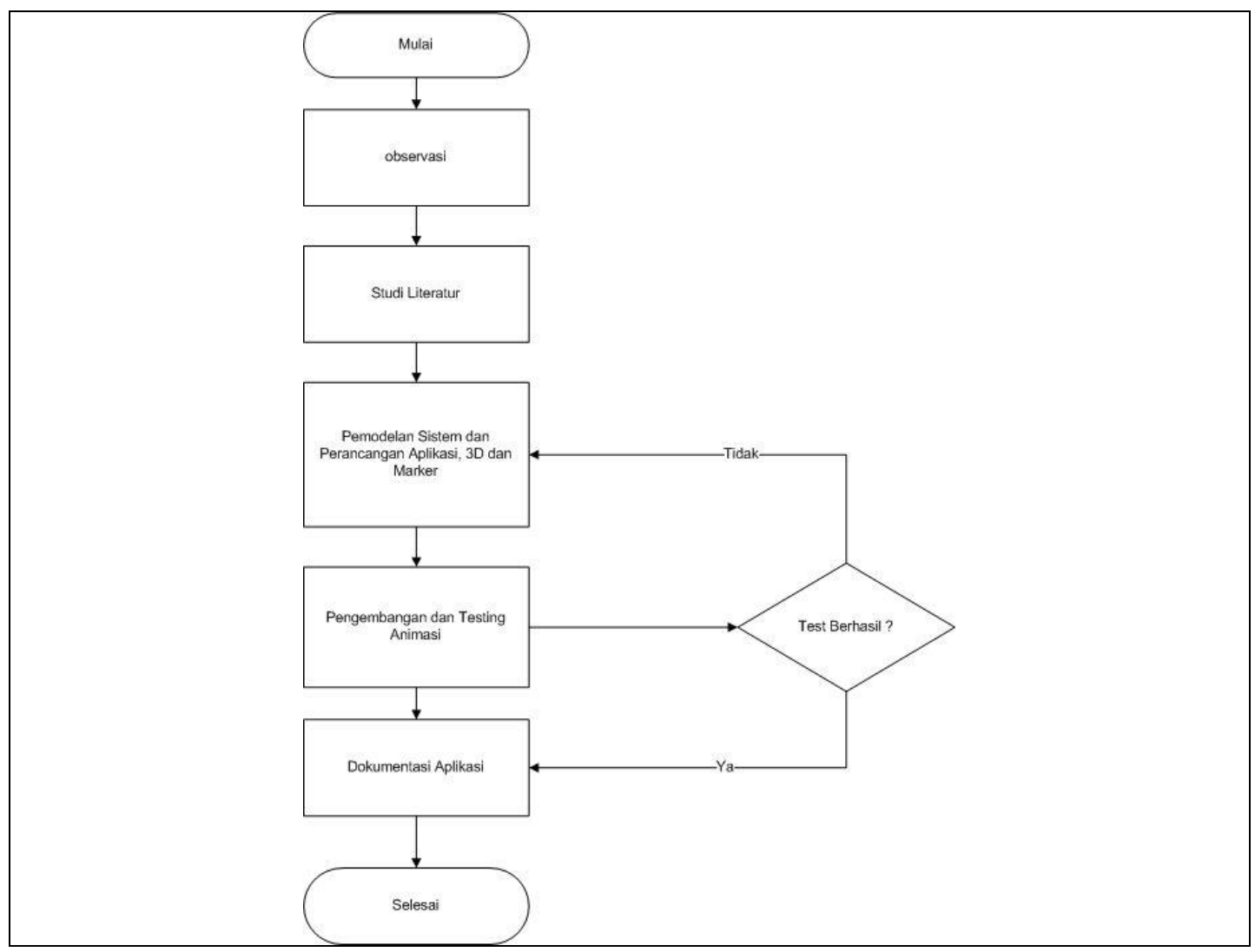

Gambar 1. Fowchart Metode Pelaksanaan

Gambar 1. Merupakan tahapan-tahapan metodologi penelitian DSRM pada penelitian Aplikasi Augmented Reality Video Dinamis "Circulation Blood Of Heart".

\subsection{Observasi (Observation)}

Observasi Augmented Reality Video Dinamis dalam Pembelajaran Peredaran Darah Berbasis Android ini menggunakan metode menganalisis dan mengadakan pencatatan secara sistemanis keadaan lingkungan seperti melalua survey langsung ke lapangan dengan target anak-anak SMP. Survey dilakukan rata-rata kepada siswa kelas 2 SMP.

\subsection{Studi Literatur (Literature Review)}

Studi literature yang digunakan pada Augmented Reality Video Dinamis dalam Pembelajaran Peredaran Darah Berbasis Android untuk pengumpulan data dan informasi dengan cara menggali pengetahuan atau ilmu dari jurnal internasional, jurnal lontar dan merpati buku skripsi atau tugas akhir yang berkaitan dengan augmented reality, maupun karya tulis yang berkaitan dengan augmented reality. Bahan video yang digunakan pada video dinamis di download dan bersumber pada youtube.

\subsection{Pemodelan Sistem, Perancangan Aplikasi, Gambar 3D dan Marker}


Pemodelan dan perancangan pada Augmented Reality Video Dinamis dalam Pembelajaran Peredaran Darah Berbasis Android dirancang menggunakan gambaran umum sistem, diagram tree, diagram konteks dan data flow diagram (DFD). Gambar 3D dan marker dirancang menggunakan sebuah aplikasi yaitu software Blender untuk pembuatan gambar 3D dan perancangan marker pada Vuforia dan Unity.

\subsection{Pengembangan Aplikasi dan Testing Aplikasi Augmented Reality}

Pengembangan aplikasi adalah tahapan dimana untuk memperbaiki kesalahankesalahan kecil dalam pengembangan yang diakibatkan oleh error karena kesalahan rancangan awal. Tools yang digunakan adalah software Unity dan Autodesk Maya sebagai perancangan desain 3D.

Testing dilakukan dua tahap. Pertama dengan menginstal apk dari aplikasi pada OS android yang kemudian dijalankan untuk menemukan kesalahan yang mungkin terjadi. Uji coba berhasil maka langsung dilanjutkan kebagian dokumentasi laporan. Kedua dengan cara orang luar dengan mengisi penilaian kuesioner apakah aplikasi sudah berjalan sesuai harapan atau tidak.

\subsection{Dokumentasi Laporan}

Dokumentasi laporan dibuat pada akhir setelah uji coba berhasil dilalui dan dapat menyelesaikan masalah dimana pembuatan laporan ini dimaksudkan agar memberikan dokumentasi atas apa saja yang dilakukan untuk digunakan oleh pihak yang memerlukan dari laporan ini

\subsection{Gambaran Umum Aplikasi}

Gambaran umum sistem dari Aplikasi Augmented Reality Video Dinamis "Circulation Blood Of Heart" merupakan aplikasi yang menampilkan gambar 3 dimensi tentang detail dari organ jantung dan peredaran darah pada jantung dengan informasi fungsi setiap detail masingmasing organ.

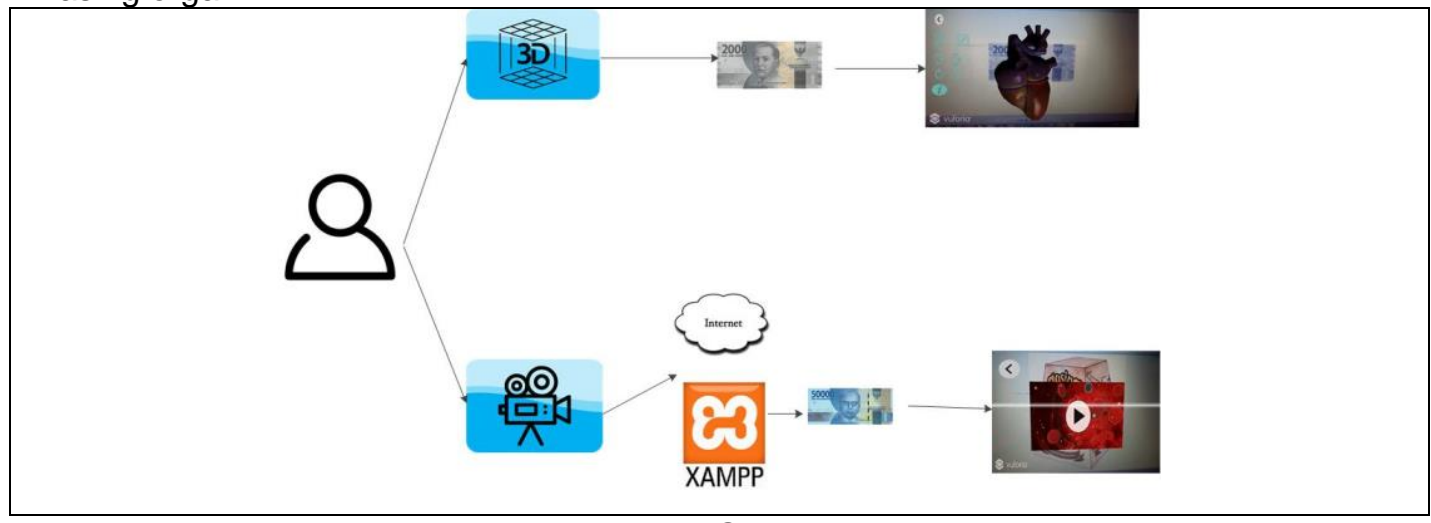

Gambar 2 Gambaran Umum

Gambaran umum meliputi proses user menggunakan aplikasi ini. User menemukan dua menu yaitu Model 3D Statis dan Video Dinamis. Model 3D Statis menggunakan marker yang telah disediakan kemudian muncul objek 3D yang telah dibuat. Video Dinamis menggunakan metadata sehingga harus menggunakan cloud dan metadata file *txt yang telah ter-upload pada cloud tersimpan pada XAMPP. XAMPP harus hidup untuk melanjutkan proses selanjutnya. User juga harus melakukan IPCONFIG pada CMD untuk mengecek apakah IP sudah terhubung ke PC. Arahkan device ke marker, maka muncul tracking dan terlihat tombol play. User harus mengklik tombol play tersebut agar video dapat berjalan.

\section{Kajian Pustaka}

Kajian pustaka memuat materi yang menjadi referensi penelitian. Referensi yang dimuat yaitu tentang peredaran darah dan augmented reality. Kedua referensi untuk kajian pustaka dimuat dalam pembahasan 3.1 dan 3.2.

\subsection{Peredaran Darah}

Penerapan Augmented Reality Video Dinamis dalam Pembelajaran Peredaran Darah 
Darah adalah pembawa molekul oksigen yang sangat penting. Serangkaian reaksi yang dilalui di mana oksigen yang terlibat, energi dihasilkan, yang diperlukan untuk mengemudi reaksi metabolisme sel-sel kita. Darah tidak mencapai bagian tubuh, kondisi dari itu adalah konsekuensi dari kekurangan oksigen. Jantung, melalui aksinya memompa, mempertahankan tekanan yang dibutuhkan untuk darah untuk mencapai semua bagian tubuh. Keadaan normal, arteri, vena dan kapiler, dimana darah melakukan perjalanan, cukup fleksibel. Terdapat dua jenis peredaran darah secara umum.

Peredaran darah kecil disebut juga peredaran darah paru-paru. Peredaran ini dimulai dari darah kotor yang berada di dalam bilik kanan jantung terpompa keluar (saat jantung berkontraksi), menuju ke arteri pulmonalis. Dibandingkan dengan peredaran darah kecil, peredaran darah besar lebih luas lintasannya. Pada peredaran darah besar, darah harus mencapai berbagai organ dan bagian tubuh atas maupun bawah. Peredaran darah besar disebut pula peredaran darah tubuh karena darah mengalir dari jantung ke seluruh tubuh dan kembali lagi ke jantung.

\subsection{Augmented Reality}

Augmented Reality merupakan teknologi terbaru yang diterapkan dengan mewujudkan benda maya ke dalam dunia nyata dan memproyeksinya secara realtime. Penjelasan Augmented Reality menurut Ronald T. Azuma (1997) yaitu penggabungan benda real dan virtual berjalan secara real time. Stephen Cawood \& Mark Fiala menjelaskan Augmented Reality yang tertuang pada buku "Augmented Reality: a practical guide" merupakan suatu cara alamiah dalam mengeksplorasi objek 3 Dimensi dengan Work Reality (Yudhastara, Brian 2012).

\section{Hasil dan Pembahasan}

Penelitian yang dilakukan menghasilkan sebuah aplikasi Android bernama Circ.BloodOfHeart. Aplikasi dapat berfungsi pada smartphone dengan spesifikasi minimal Android KitKat. Aplikasi dapat digunakan sesuai fungsinya pada processor Quadl-Core $1.2 \mathrm{GHz}$ dan RAM 2GB. Marker pada video dinamis bersifat dinamis, karena telah disimpan di server local. Penerapan AR dengan marker dinamis mengakibatkan diperlukannya koneksi internet stabil dari IP yang telah di setting ketika menjalankan aplikasi.

\subsection{Scene Main Menu}

Main menu menampilkan empat menu utama yang bisa di mainkan oleh user berfungsi dalam mempermudah memilih menu pada Aplikasi ARCirc.BloodOfHeart. Tampilan scene main menu dapat dilihat pada Gambar 6.

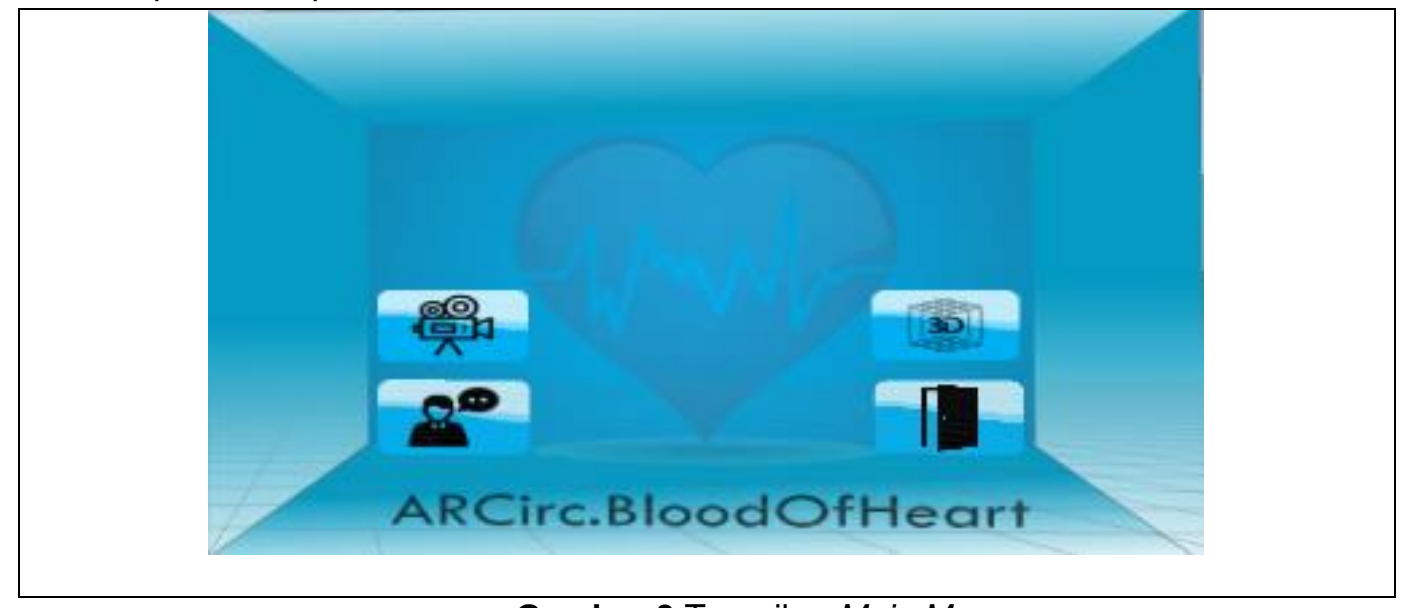

Gambar 3 Tampilan Main Menu

Gambar 3 menampilkan scene menu utama Aplikasi ARCirc.BloodOfHeart. Tampilan tersebut berisikan empat menu utama yang dapat memudahkan dalam pemakaiannya. Empat main menu tersebut yaitu menu Model, menu Video, menu About dan menu Exit. 


\subsection{Scene AR Model}

Scene AR Model merupakan menu utama untuk men-scan dan memunculkan 3D organ jantung dan 3D peredaran darah. Tampilan scene Augmented Reality Model dapat dilihat pada Gambar 4.

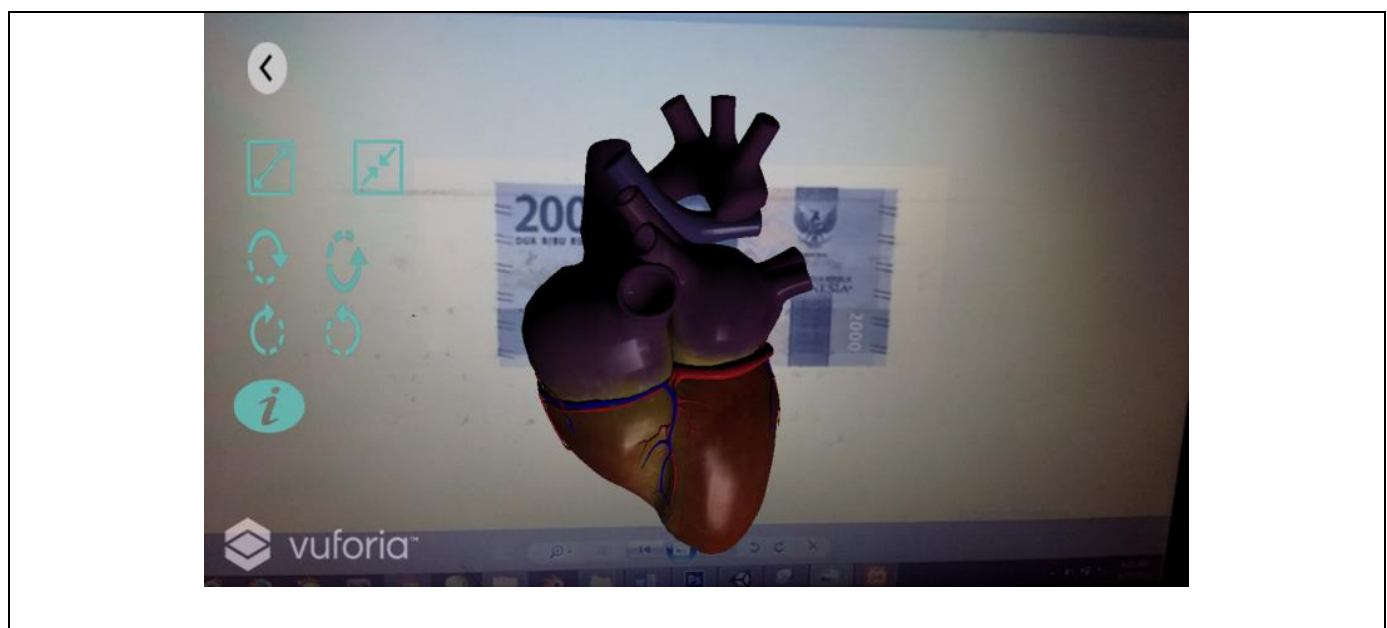

Gambar 4 Tampilan Scene Augmented Reality Model

Tampilan memiliki beberapa tombol yang dijalankan Aplikasi ARCirc.BloodOfHeart. Tombol tersebut yaitu Tombol Info, Tombol Rotate dan Tombol Zoom serta Tombol Back. Tombol Info berfungsi memberikan informasi pada 3D yang di-tracking. Tombol Rotate berfungsi untuk memutar 3D agar mempermudah melihat bagian atas, bagian bawah, bagian kanan dan bagian kiri. Tombol Zoom berfungsi untuk mengubah model animasi 3D. Tampilan fitur Zoom In dapat dilihat pada Gambar 5

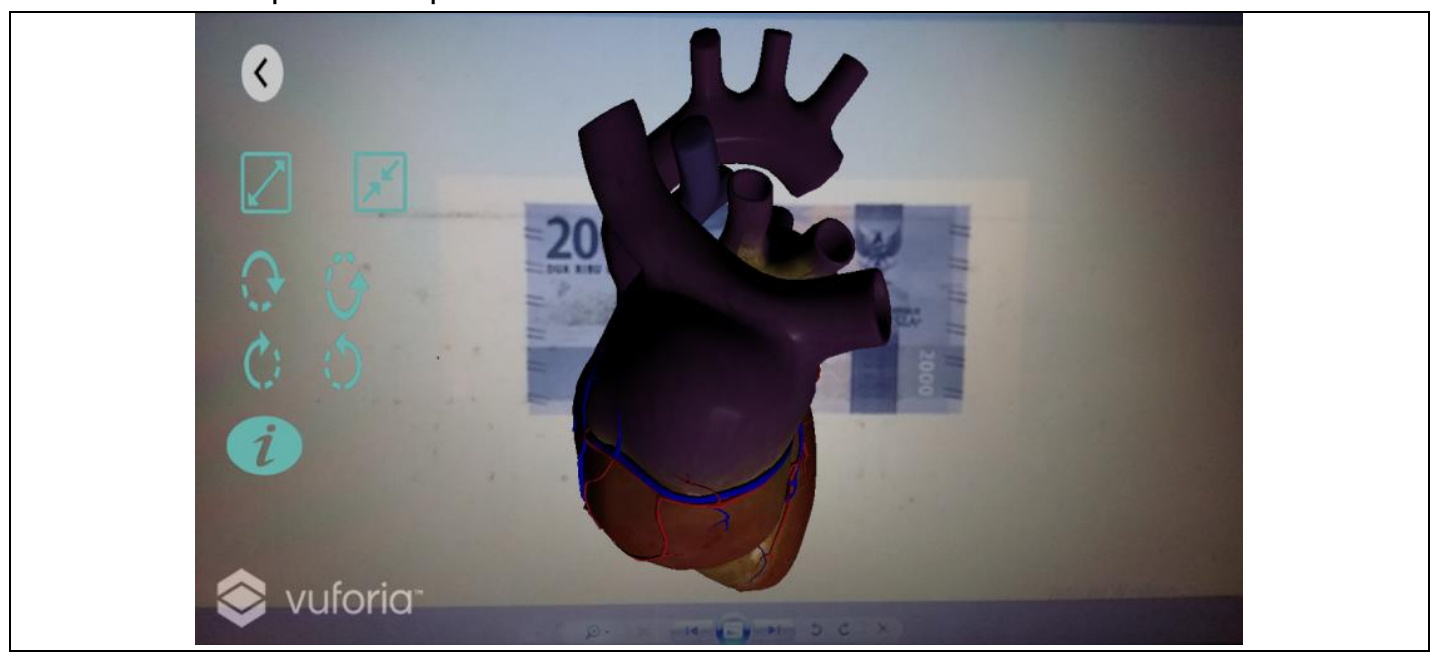

Gambar 5 Fitur Zoom In

Menu Zoom In pada Model berfungsi memperbesar objek dari model yang telah ditracking, sehingga user dapat melihat bagian-bagian objek secara jelas. Tampilan fitur Zoom Out dapat dilihat pada gambar berikut. 


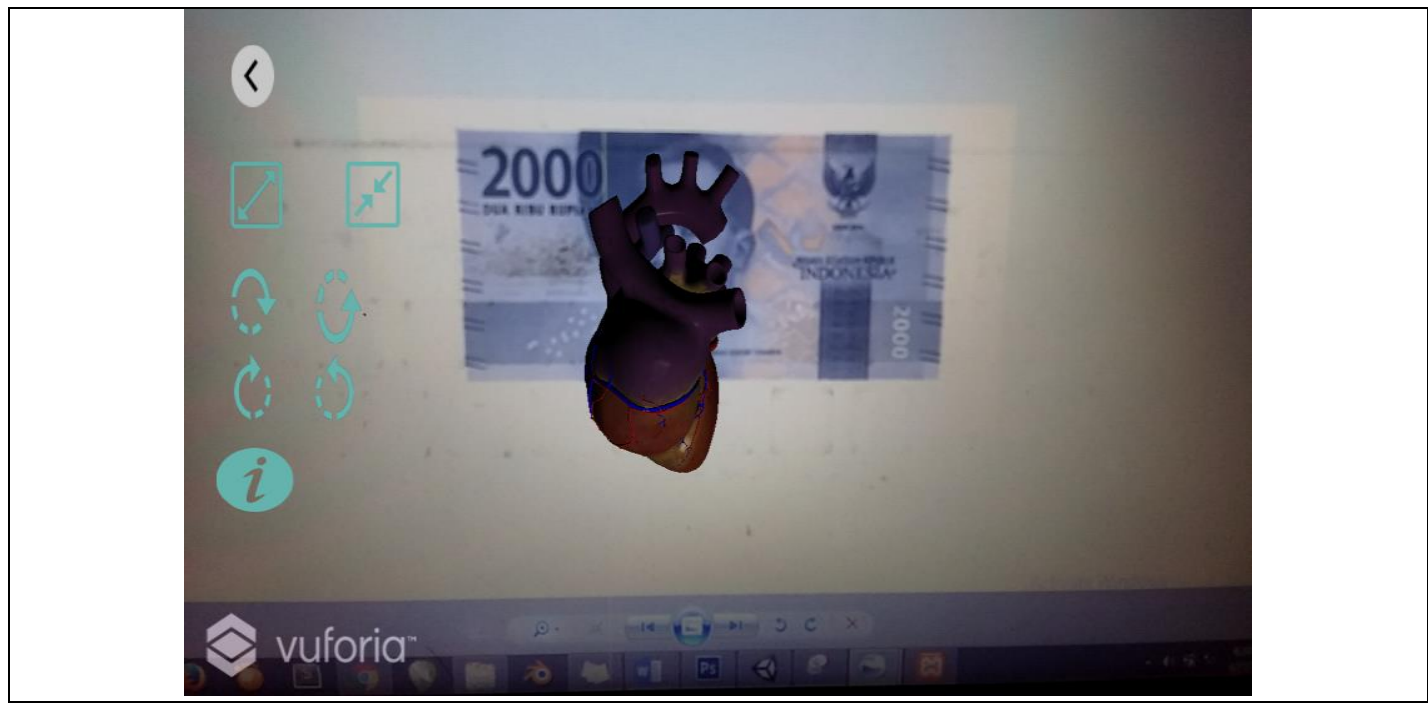

Gambar 6 Fitur Tombol Zoom Out

\subsection{Video Dinamis}

Scene video ini merupakan scene yang menaampilkan hasil marker dalam bentuk video dinamis dengan format video yaitu MP4. Tampilan scene Video Dinamis dapat dilihat sebagai berikut.

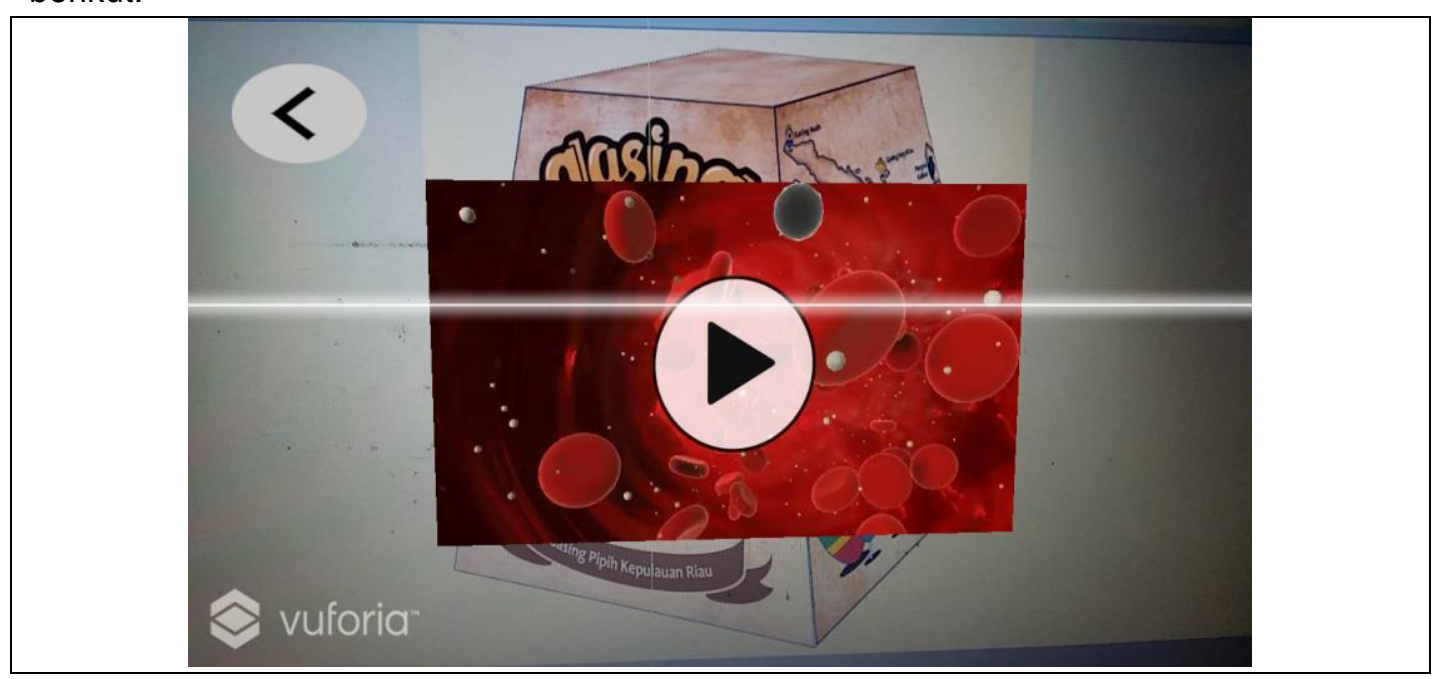

Gambar 7 Tampilan Tracking Video Dinamis

Gambar 7 memperlihatkan tampilan mengenai Tracking pada scene Video Dinamis. Tampilan berikutnya adalah pada saat video berhasil di putar dapat dilihat pada Gambar 11 


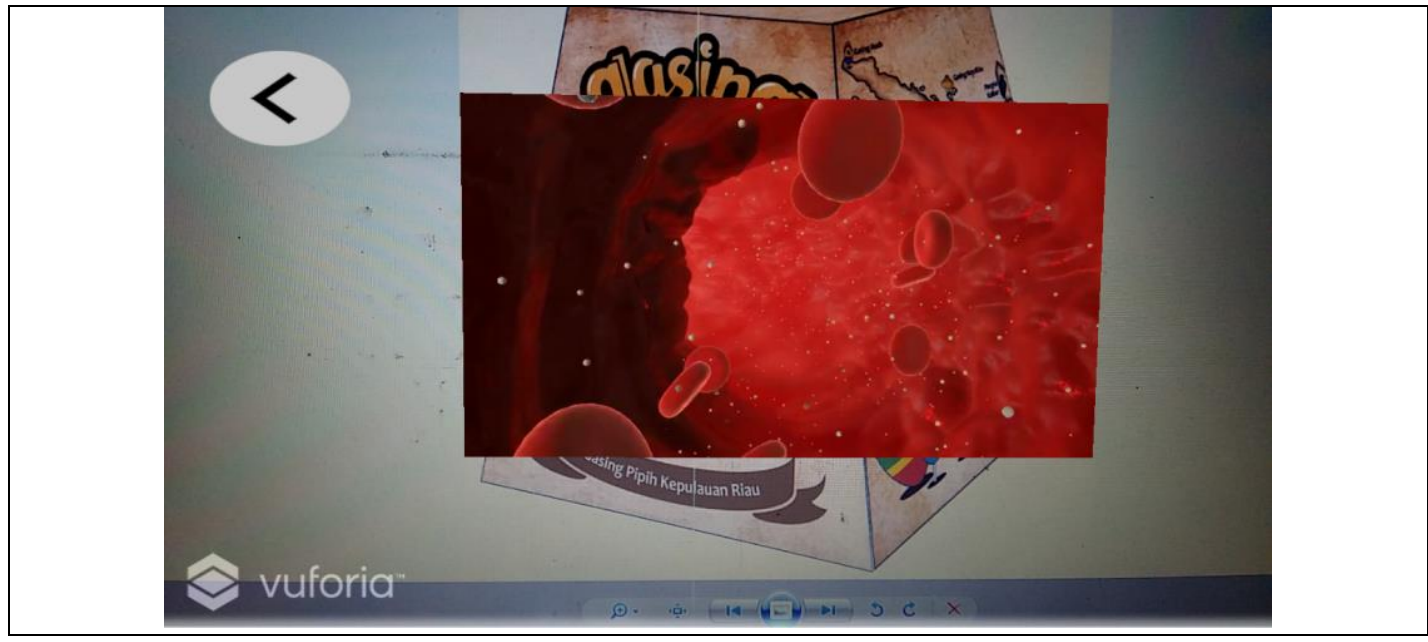

Gambar 8 Tampilan Video dari Video Dinamis

Gambar 8 memperlihatkan isi dari scene Video Dinamis setelah video berhasil di tracking dan dapat di-play.

Video dinamis pada aplikasi ARCirc.BloodOfHeart merupakan sebuah aplikasi Augmented Reality yang bersifat dinamis karena menggunakan cloud metadata dan server local untuk meng-upload marker dan melakukan update pada marker maupun pada content video tersebut. Contoh metadata yang disimpan pada local adalah sebagai berikut.

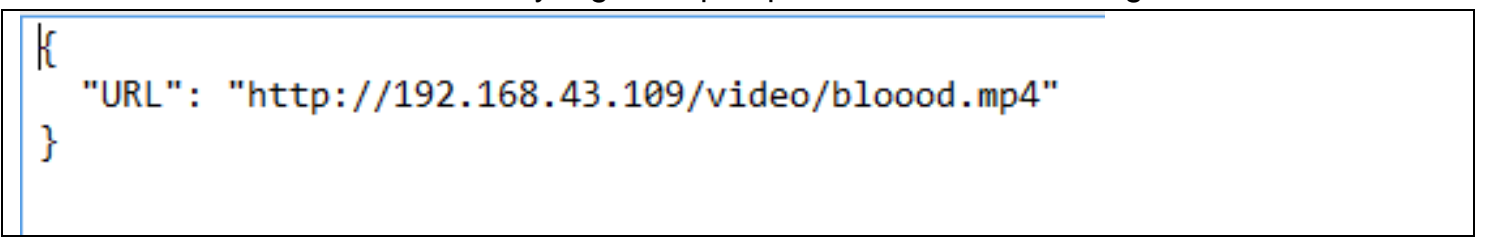

Kode Program 1 Metadata

Kode Program 1 merupakan contoh metadata yang disimpan pada server local. Metadata merupakan suatu informasi tambahan yang dibawa oleh setiap marker pada Vuforia. Metadata dapat berisi suatu perintah untuk melakukan sesuatu. Metadata berisi URL yang menunjukkan lokasi penyimpanan.

\subsection{Fitur Update Target Video Dinamis}

Video dinamis pada aplikasi ARCirc.BloodOfHeart memiliki fitur yaitu dapat melakukan update marker pada vuforia. Update pada vuforia dapat dilihat sebagai berikut. 


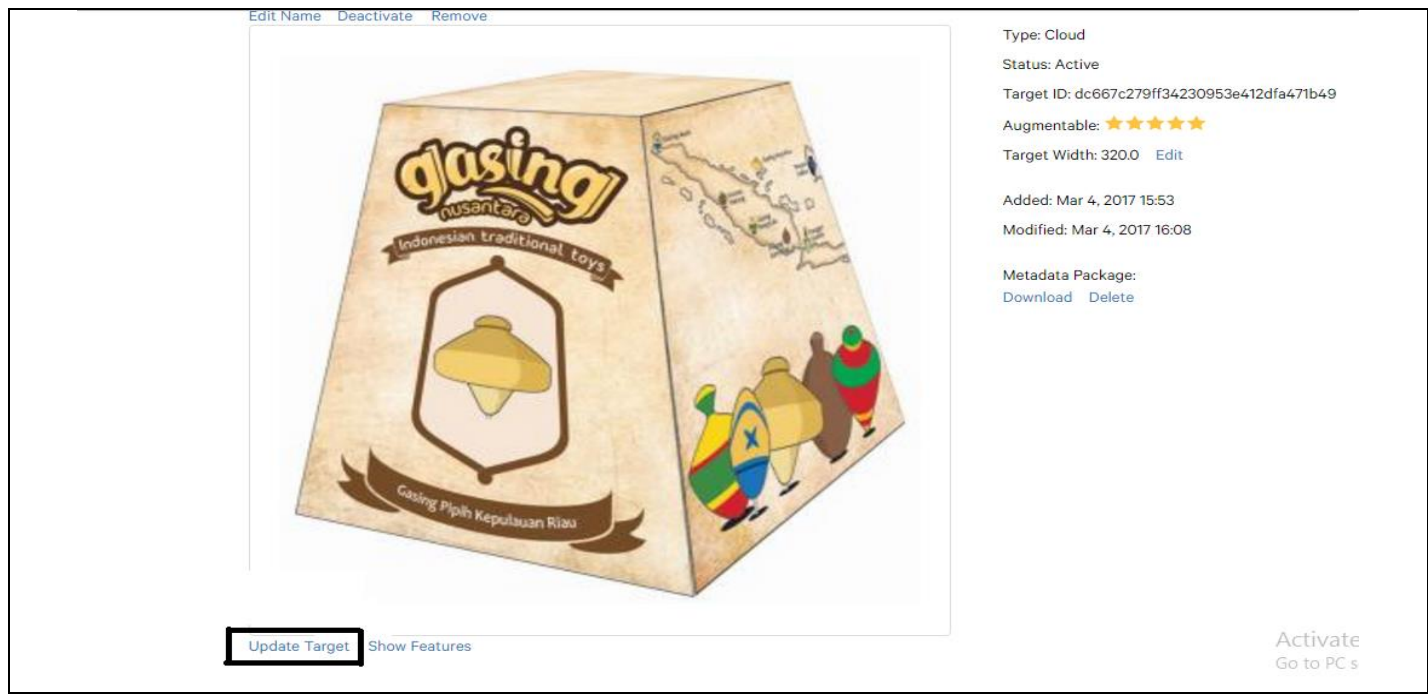

Gambar 9 Update Target Video Dinamis pada Vuforia

Gambar 9 merupakan gambar update target pada video dinamis di vuforia. Admin hanya boleh meng-update target dengan format jpg. Berikut hasil update target pada video dinamis di vuforia.

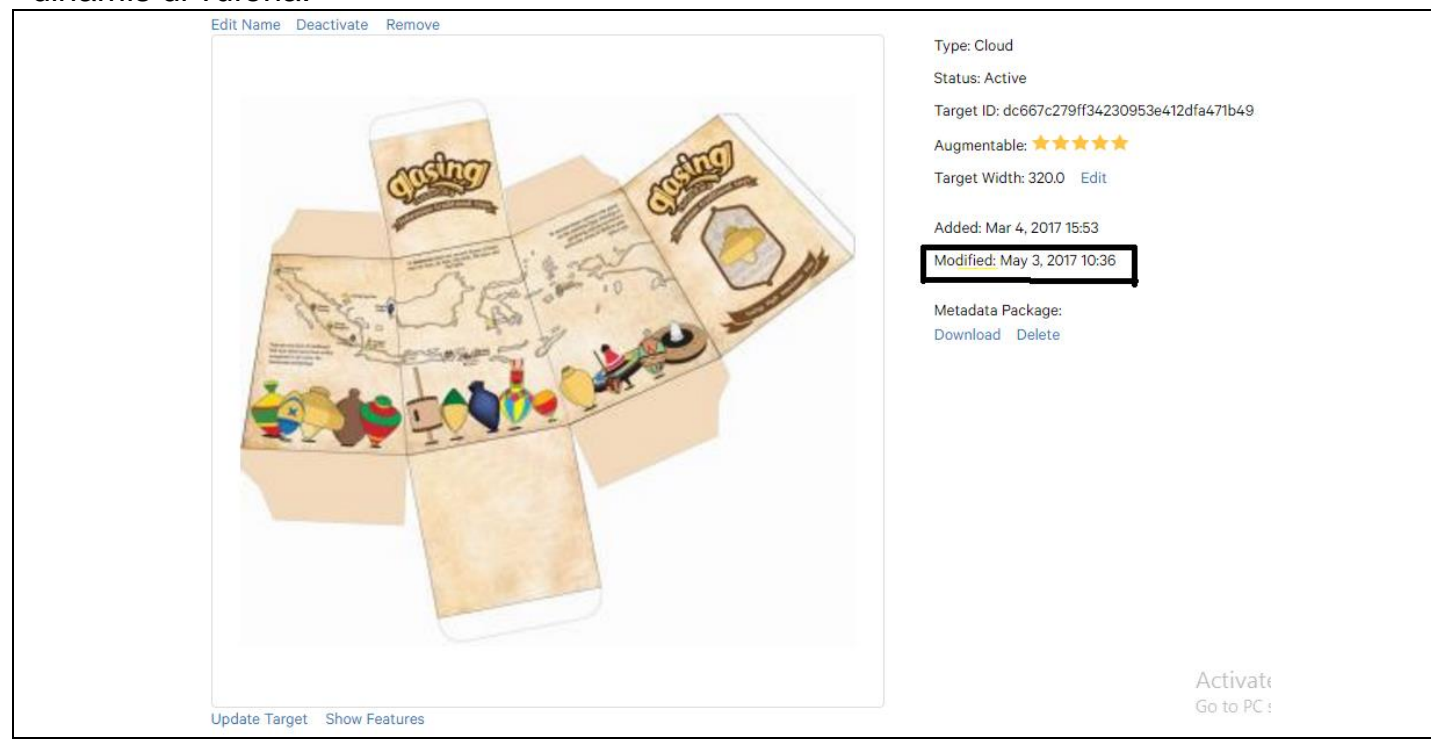

Gambar 10 Hasil Update Target di Vuforia

Gambar 10 memperlihatkan hasil dari meng-update target pada aplikasi ARCirc.BloodOfHeart. Hasil update dapat dilihat pada tulisan modified terakhir yang dilakukan. Fitur selanjutnya adalah fitur update content video pada server local.

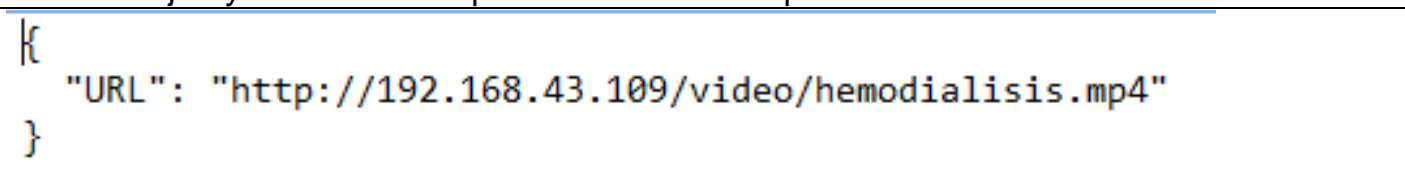

Kode Pogram 2 Metadata pada Server Local

Kode Program 2 memperlihatkan isi metadata pada server local di Xampp untuk melakukan update content video. Update video ini memerlukan IP yang sama dari smartphone dan laptop serta Xampp pada laptop juga harus dalam keadaan "start". Admin memilih video untuk bahan update, kemudian admin melakukan paste pada video tersebut di folder yang sama dengan metadata. Video yang telah di paste dilakukan rename sesuai nama metadata. Metadata diatas contohnya dengan nama hemodialasis. Hasil update dapat dilihat pada marker atau target dengan nama metadata adalah "hemodialisis". 


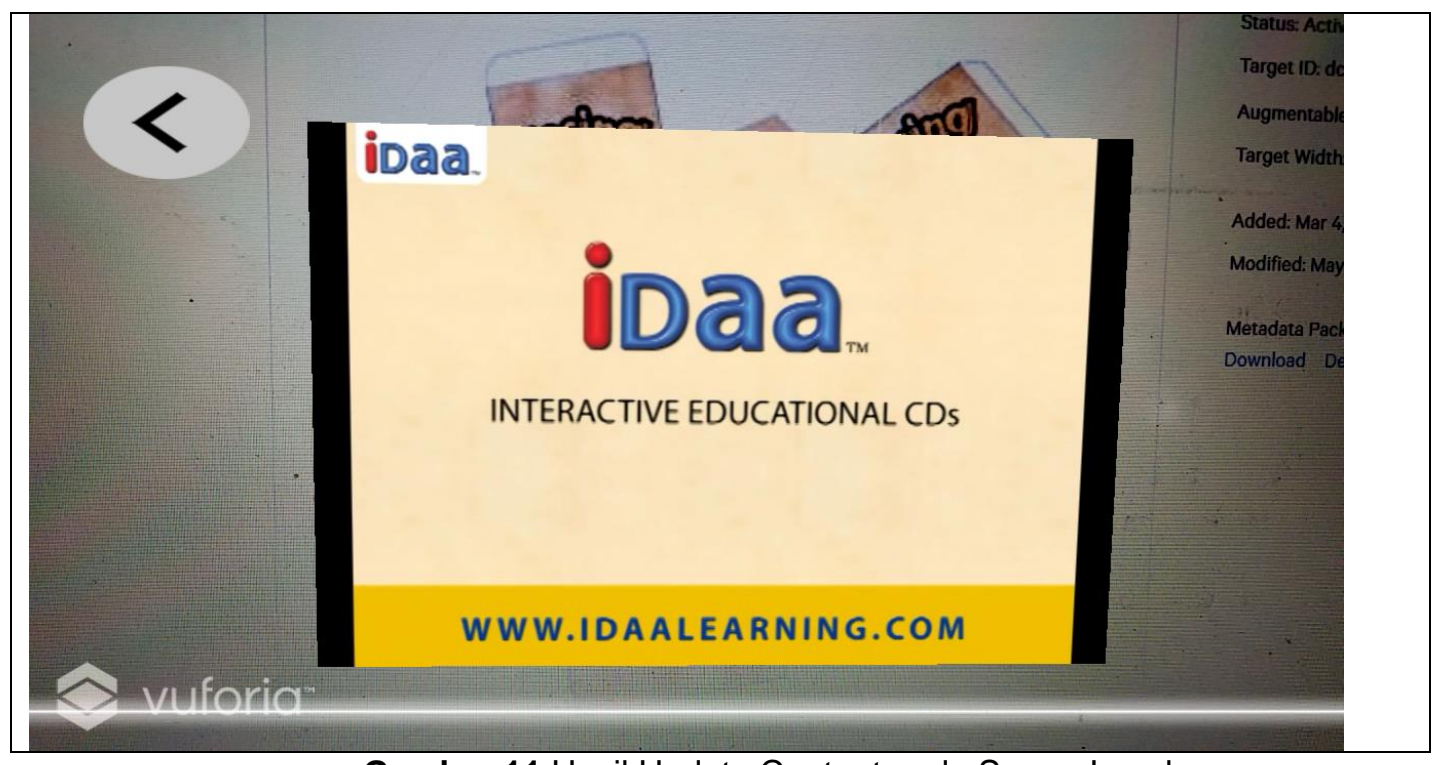

Gambar 11 Hasil Update Content pada Server Local

Gambar 11 adalah hasil update dari content video dinamis pada server local. Video content dapat di-play dan di-pause pada target yang sama.

\section{Kesimpulan}

Kesimpulan dari Penerapan Augmented Reality Video Dinamis dalam Pembelajaran Peredaran Darah Berbasis Android ini berupa aplikasi yang dijalankan dalam perangkat mobile Android 3D dalam konten 3D statis dan video dinamis serta dapat memberikan informasi mengenai peredaran darah pada jantung. Kesimpulan terakhir menurut berdasarkan penilaian responden yaitu adalah baik, dengan pencapaian persentase grafis $64 \%$, presentase rekayasa perangkat lunak $71 \%$ dan presentase entertainment application $81 \%$. Aplikasi untuk kedepannya agar dapat dikembangkan dengan menggunakan metode markerless sehingga lebih menarik lagi untuk minat belajar para siswa.

\section{Daftar Pustaka}

[1] I. G. A. Nugraha, I. K. G. D. Putra, and I. M. Sukarsa, "Rancang Bangun Aplikasi Android AR Museum Bali: Gedung Karangasem dan Gedung Tabanan," Lontar Komputer, vol. 7, no. 2, pp. 93-103, 2016.

[2] I. D. G. W. Dhiyatmika, I. K. G. D. Putra, and N. M. I. M. Mandenni, "Aplikasi Augmented Reality Magic Book Pengenalan Binatang untuk Siswa TK," Lontar Komputer, vol. 6, no. 2, pp. 120-127, 2015.

[3] N. P. S. Franza, A. A. K. Oka Sudana, and K. S. Wibawa, "Application of Basic Balinese Dance Using Augmented Reality on Android," Journal of Theoretical and Applied Information Technology, vol. 90, no. 1, pp. 61-66, 2016.

[4] G. Y. P. Pangestu, N. M. I. M. Mandenni, and N. K. D. Rusjayanthi, "Aplikasi Web Augmented Reality Villa," Merpati, vol. 5, no. 1, pp. 29-40, 2017.

[5] A. F. Waruwu, I. P. A. Bayupati, and I. K. G. Darma Putra, "Augmented Reality Mobile Application of Balinese Hindu Temples: DewataAR," International Journal of Computer Network and Information Security, vol. 7, no. 2, pp. 59-66, 2015.

[6] G. Javadian Dehkordi, S. Rezvani, M. Sabbir Rahman, F. Fouladivanda, and S. Faramarzi Jouya, "A Conceptual Study on E-marketing and Its Operation on Firm's Promotion and Understanding Customer's Response," International Journal of Business and Management, vol. 7, no. 19, pp. 114-124, 2012.

[7] S. C. Y. Yuen, G. Yaoyuneyong, and E. Johnson, "Augmented Reality: An Overview and Five Directions for AR in Education," Journal of Educational Technology Development and Exchange, vol. 4, no. 1, pp. 119-140, 2011.

[8] H. Ling, "Augmented Reality in Reality," IEEE Multimedia, vol. 24, no. 3, pp. 10-15, 2017. 
